\title{
CHEMICAL AND ELECTROTONIC CONNECTIONS BETWEEN APLYSIA NEURONS IN PRIMARY CULTURE
}

\author{
ROLF BODMER,* DANIEL DAGAN, $\ddagger,{ }^{\prime}$ AND IRWIN B. LEVITAN, $\S^{2}$ \\ * Friedrich Miescher-Institut, P. O. Box 2543, CH-4002 Basel, Switzerland, $\ddagger$ Department of Physiology, Technion Medical \\ School, Haifa, Israel, and $\S$ Graduate Department of Biochemistry, Brandeis University, Waltham, Massachusetts 02254
}

Received May 20, 1983; Revised August 12, 1983; Accepted August 16, 1983

\begin{abstract}
Dissociated Aplysia neurons will regenerate neurites and form functional connections in primary cell cultures. The specificity of intercellular connectivity in these cultures was investigated by coculturing neurosecretory bag cells with neurons dissociated from the buccal ganglion. It was found that bag-bag and buccal-buccal electrotonic synapses form with high frequency, consistent with previous findings in pure bag and buccal cultures. There is specificity in the formation of these connections, since no bag-buccal electrotonic synapses were observed. Chemical interactions, on the other hand, are present between bag and buccal neurons. In a buccal-bag pair, injection of sufficient depolarizing current into the buccal cell to elicit a train of action potentials leads to a slow hyperpolarizing response in the bag cell. The bag cell hyperpolarization is accompanied by an increase in the cell's input conductance. This connection appears to be unidirectional, produces a voltage shift in the bag cell which is opposite in sign to that in the buccal cell, and is blocked by the removal of $\mathrm{Ca}^{2+}$ from the extracellular medium, indicating that it is mediated by a chemical neurotransmitter. The selective formation of electrotonic synapses in these mixed bag-buccal cultures, together with the presence of chemically mediated interactions, make this system particularly useful for investigating the establishment of intercellular connectivity.
\end{abstract}

The functioning of the nervous system is dependent on highly specific intercellular interactions. These interactions are in turn dependent on the formation of appropriate synaptic connections during development. In addition recovery of function after injury to the nervous system may depend on regeneration of neurites and reformation of appropriate synapses. To date relatively little is known about the cues neurons use to recognize appropriate partners and form specific synaptic connections during development and regeneration.

It is clear that many aspects of nervous system development can best be studied in whole animals. On the other hand synaptic specificity in vivo may depend at least in part on mechanical barriers which allow only appropriate cells access to one another; such constraints are largely absent in cell cultures, and thus questions relating to cellular specificity in synaptogenesis may be more readily attacked. These advantages have led to the widespread use of cultured nerve and muscle cells to study mechanisms and specificity of synaptogenesis (for

\footnotetext{
${ }^{1}$ Short-term fellow of the European Molecular Biology Organization.

${ }^{2}$ To whom correspondence should be addressed, at the Graduate Department of Biochemistry, Brandeis University, Waltham, MA 02254 .
}

reviews see Nelson, 1975; Fischbach and Nelson, 1977). The recent development of techniques for the culturing of certain large invertebrate neurons (Kaczmarek et al., 1979; Ready and Nicholls, 1979; Wong et al., 1981; Dagan and Levitan, 1981; Schacher et al., 1982) has opened up the possibility of investigating specificity of synapse formation between individual cells or groups of cells. It has been reported that Aplysia neurosecretory bag cells readily form electrotonic synapses with each other in culture (Kaczmarek et al., 1979). Cultured neurons from the Aplysia buccal ganglion also form electrotonic synapses with each other with high frequency (Dagan and Levitan, 1981), far higher than has been reported in the intact ganglion (Gardner, 1971, 1977), suggesting that electrotonic coupling in these cultures might be indiscriminate. In order to determine whether there is indeed cellular specificity in the formation of these synapses, we prepared mixed cultures containing both bag and buccal neurons. We report here that, although bag-bag and buccal-buccal electrotonic synapses form readily in such mixed cultures, no bag-buccal electrotonic connections were found. On the other hand we often observed a novel buccal-to-bag cell inhibitory chemical interaction, even though bag and buccal cells have not been reported to make functional contacts in situ. 


\section{Materials and Methods}

Cell culture. Adult Aplysia californica weighing 100 to $250 \mathrm{gm}$ were obtained from Marine Specimens Unlimited, Pacific Palisades, CA, and were maintained in artificial sea water (Instant Ocean). Cell culturing was carried out as described by Dagan and Levitan (1981). Buccal and abdominal ganglia were incubated overnight in artificial sea water containing neutral protease (Kaczmarek et al., 1979; Dagan and Levitan, 1981). The bag cell clusters were dissected away from the abdominal ganglia, and the softened connective tissue sheath was removed from the buccal ganglia and hag cell clusters. The neurons were mechanically dissociated on glass coverslips in salt-supplemented L-15 (Gibco) tissue culture medium containing $4 \%$ fetal calf serum and $1 \%$ methyl cellulose, and the cultures were incubated at room temperature as described previously (Dagan and Levitan, 1981).

Intracellular recording. Electrophysiological experiments were performed, using conventional techniques, on the stage of a Zeiss IM35 inverted microscope equipped with phase contrast optics. Prior to recording, the culture dishes were perfused with artificial sea water to remove the methyl cellulose. Individual neurons were impaled with microelectrodes containing $3 \mathrm{M} \mathrm{KCl}$. The electrode resistances were 10 to 20 megohms. Cellular input conductances were determined by injecting pulses of inward (hyperpolarizing) current through the recording electrode. The voltage drop across the electrode was circumvented by means of a chopped current injection device designed and built by $W$. B. Adams (unpublished procedure). The cells had resting potentials between -20 and $-40 \mathrm{mV}$, and some were hyperpolarized to between -40 and $-50 \mathrm{mV}$ to prevent endogenous firing. For measurements of electrotonic coupling hetween pairs of cells, positive and negative current pulses were delivered first to one and then to the other cell of the pair, and the membrane potential changes in both cells were measured. Injections into only one cell per pair are shown, but the electrotonic spread was qualitatively the same in both directions. No appreciable rectification was observed that could not be accounted for by the rectifying membrane properties of the cells themselves. There was no coupling between the electrodes after their withdrawal from the cells.

\section{Results}

Electrotonic synapses. When neurons from bag cell clusters and buccal ganglia are mechanically dissociated in the same culture dish, they regenerate an elaborate network of interconnected neurites within several days (Fig. 1a). The bag cells are white and can be distinguished readily from the orange- or brown-pigmented buccal neurons under the microscope. In addition, bag cell action potentials tend to be smaller than $80 \mathrm{mV}$ in amplitude, and the cells cannot easily be fired at high frequency $(>10 \mathrm{~Hz})$ by a depolarizing current pulse (L. Kaczmarek, personal communication; confirmed by us). Using these criteria it is possible to unequivocally identify a given cell as either bag or buccal (Fig. 1b) and to impale either bag-bag, buccal-buccal, or bag-buccal cell pairs to test for functional connectivity. The experiment described in Figure 2 was performed with the two bag and two buccal neurons illustrated and labeled in Figure $1, a$ and $b$. As shown in Figure 2a, hyperpolarizing current injected into bag cell $\mathrm{BG} 1$ produces voltage changes in both BG1 and BG2, indicating that these two bag cells are electrotonically connected (coupling coefficient = 0.1 ). A similar result was obtained when current was injected into BG2 and when depolarizing current pulses were used (not shown). Similarly, there is an electrotonic synapse between the two buccal neurons $\mathrm{BC} 1$ and $\mathrm{BC} 2$ (Fig. 2b; coupling coefficient $=0.1$ ). These results are consistent with previous findings in pure bag (Kaczmarek et al., 1979) and buccal (Dagan and Levitan, 1981) cultures.

In contrast there is no detectable voltage change in $\mathrm{BC} 1$ when either depolarizing or hyperpolarizing current is injected into BG1 (Fig. $2 c$; coupling coefficient $<0.02$, the minimum reliably detectable), indicating that a bagbuccal electrotonic synapse is not present. Similarly, there is no transfer of current from BG2 to BC2 (not shown). It is possible that the bag-buccal pairs are in fact coupled but that the current transferred between them decreases to below detectable levels by the time it reaches the recording electrode in the postsynaptic cell, but this seems unlikely since the coupling between $\mathrm{BC} 1$ and $\mathrm{BC} 2$ can be observed easily (Fig. $2 b$ ), even though these cells are 300 to $400 \mu \mathrm{m}$ apart (Fig. 1).

Chemical interactions. When the buccal cell $\mathrm{BC} 1$ is taken as the presynaptic cell of the BC1-BG1 pair, injection of hyperpolarizing current does not elicit any voltage change in BG1 (not shown), confirming the absence of a bag-buccal electrotonic synapse. However, when the buccal cell $\mathrm{BC} 1$ is injected with sufficient depolarizing current to elicit a train of action potentials, a hyperpolarizing response is evoked in the bag cell BG1 (Fig. 2d). Although in this particular cell pair a relatively high frequency of buccal cell action potentials was required to elicit a response, a bag cell hyperpolarization could often be evoked by much slower buccal cell firing (Fig. 3). In this latter example the action potential frequency in the buccal cell was $6 \mathrm{~Hz}$ during the first second of depolarization (Fig. 3). Bag cell firing at up to $10 \mathrm{~Hz}$ (it was difficult to fire bag cells at higher frequencies) never elicited a response in an associated buccal cell (see, for example, Fig. $2 c, 7 \mathrm{~Hz}$ ), suggesting that the functional connection is unidirectional. The bag cell hyperpolarization is slow in onset and long outlasts the depolarization in the buccal cell (Figs. $2 d$, and 3 to 5); taken together with the facts that the response appears to be unidirectional and that buccal cell depolarization leads to bag cell hyperpolarization, this kinetics suggests that the buccal-to-bag interaction is chemically mediated. This suggestion was further tested by removing $\mathrm{Ca}^{2+}$ from the extracellular saline to inhibit the release of chemical neurotransmitters. As shown in Figure 4, removal of $\mathrm{Ca}^{2+}$ reversibly inhibits the buccal-to-bag cell hyperpolarizing response, confirming that it is chemically mediated.

Similar patterns of connectivity were observed with a large number of cell pairs in different culture dishes (Table I): bag-bag and buccal-buccal electrotonic syn- 

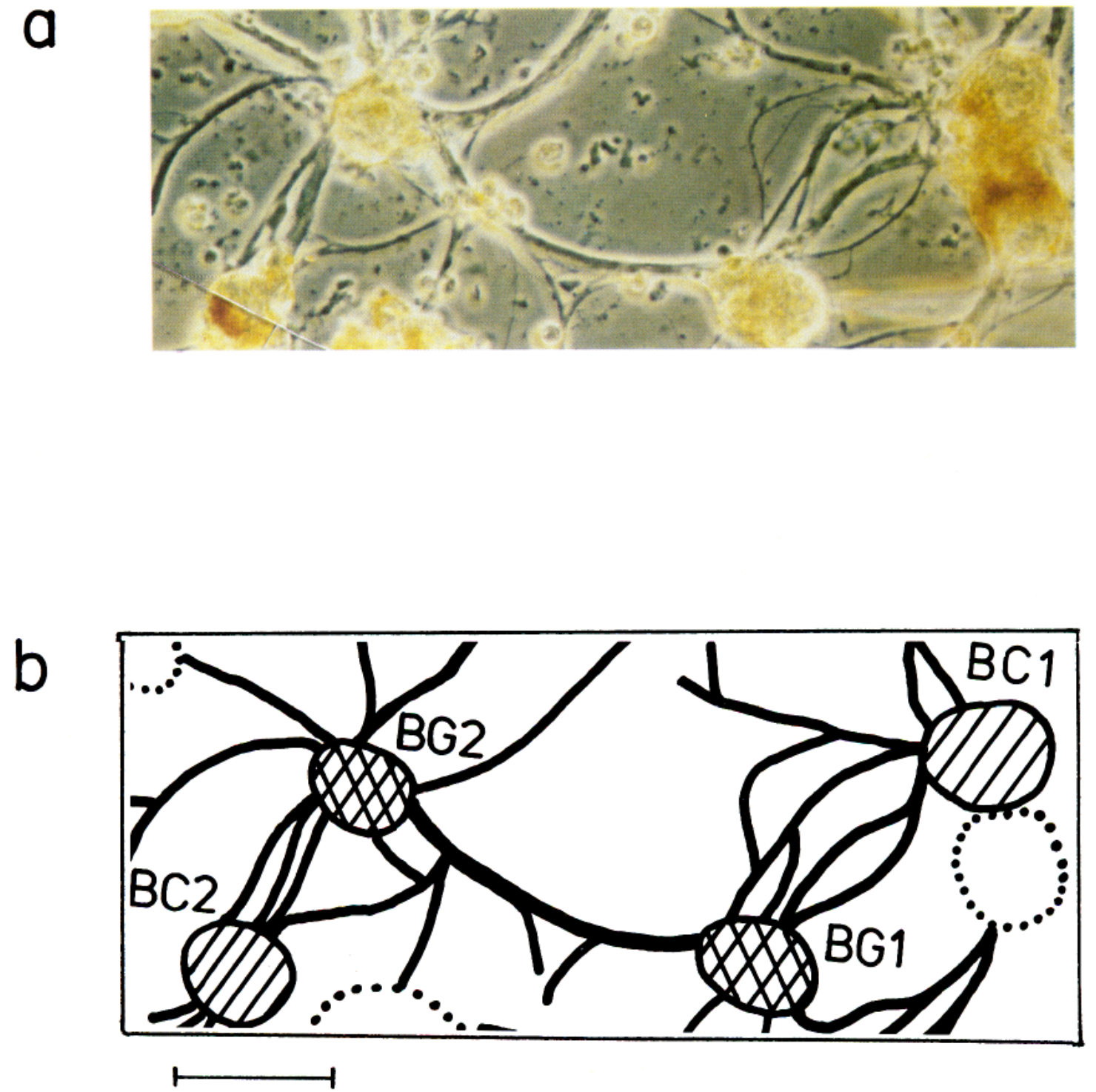

Figure 1. Morphology of mixed cultures of bag $(B G)$ and buccal $(B C)$ neurons. Cultures were prepared and maintained as described under "Materials and Methods" and were photographed using phase contrast optics. $a$, phase contrast micrograph of a typical mixed bag-buccal cell culture after 10 days in culture. An elaborate network of regenerated neurites connects the neurons. The buccal neurons are heavily pigmented, whereas the bag cells are white or only lightly pigmented. $b$, schematic representation of the microscope field in $a$. $B G 1, B G 2$ and $B C 1, B C 2$ are the bag and buccal neurons, respectively, from which the recordings in Fig. 2 were made. Bar, $80 \mu \mathrm{m}$.

apses were observed routinely; no bag-buccal electrotonic synapses were found; and the buccal-to-bag cell chemical connection was detectable between about $60 \%$ of the cell pairs tested. The coupling coefficients measured for the coupled pairs ranged from 0.02 to 0.80 (90\% between 0.05 and 0.50 ), and the bag cell hyperpolarizations ranged from 1 to $30 \mathrm{mV}$ in amplitude. These patterns established themselves after less than 4 days in culture and persisted unchanged for at least 8 weeks.

The four cells described in Figures 1 and 2 are part of a larger network containing many interconnected cells. However, it was also possible to observe the buccal-tobag chemical connection in isolated cell pairs (see, for example, Fig. 4); the frequency of occurrence and properties of the functional connections between isolated cell pairs were indistinguishable from those connections be- tween cells in a multicellular network. This indicates that a bag cell response can be elicited by the firing of a single buccal neuron and does not require the release of transmitter from other coupled cells in a network.

To determine whether bag cell input conductance changes during the buccal cell evoked hyperpolarization, hyperpolarizing current pulses were injected through the bag cell recording electrode. It was found that the voltage deflection in response to these current pulses decreases during the hyperpolarization, indicative of an increase in input conductance (Fig. 5). A preliminary investigation of the ionic basis of the response, involving voltage clamp analysis together with changes in the ionic composition of the extracellular medium, suggests that a large part of this increase in input conductance reflects an increase in conductance to $\mathrm{K}^{+}$ions. 
a
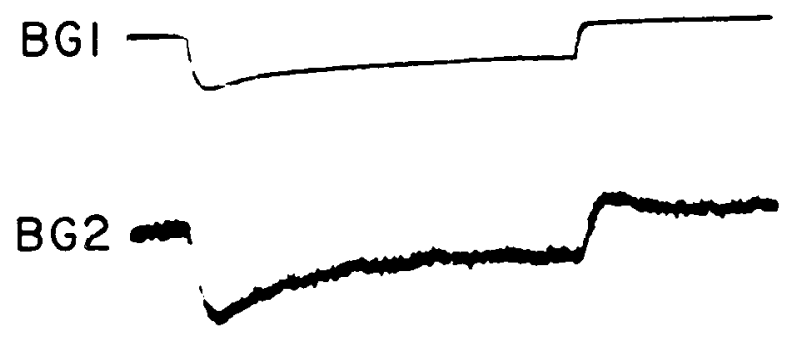

b

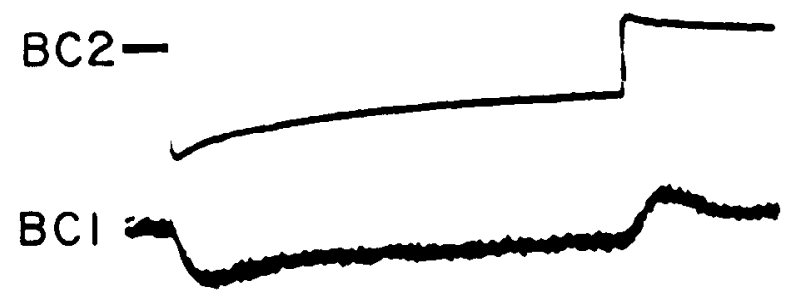

C

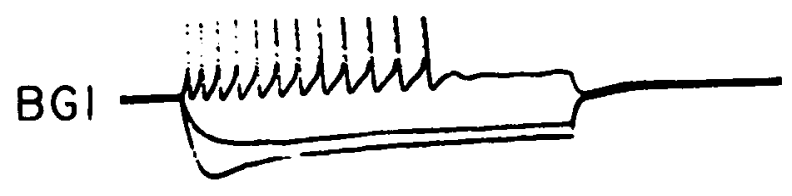

$\mathrm{BCl}$

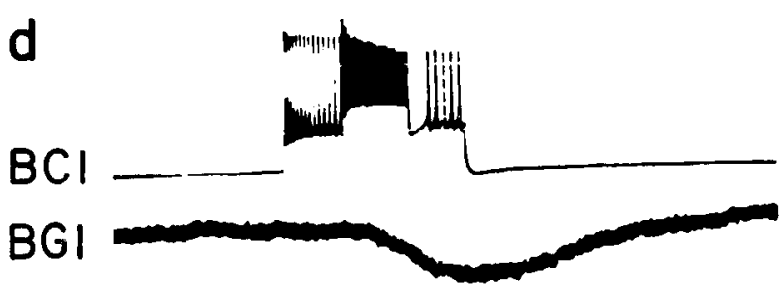

Figure 2. Electrotonic and chemical interactions in mixed cultures of bag and buccal neurons. Recordings from the cells illustrated in Fig. 1 using standard techniques as described under "Materials and Methods." $a$, coupling between $B G 1$ and $B G 2$ seen by injection of $-1 \mathrm{nA}$ into $B G 1 ; b$, coupling between $B C 1$ and $B C 2$ seen by injection of $-2 \mathrm{nA}$ into $B C 2$; $c$, no coupling between $B G 1$ and $B C 1$ (or between $B G 2$ and $B C 2$, not shown) was detectable when depolarizing or hyperpolarizing current was injected into $B G 1$ (or $B G 2)$; d, depolarizing current $(+0.7 \mathrm{nA}$, then $+1.4 \mathrm{nA}$ ) injected into $B C 1$ gave rise to high frequency firing which elicited a slow hyperpolarizing response $(4 \mathrm{mV})$ in $B G 1$. In some cell pairs the bag cell hyperpolarized by as much as 30 $\mathrm{mV}$, even when the cell bodies were several hundred $\mu \mathrm{m}$ apart. Similar results were obtained with the $B C 2-B G 2$ cell pair. Calibration: top traces, $100 \mathrm{mV}$; bottom traces, $10 \mathrm{mV}$ (except $b$, top trace, $40 \mathrm{mV}$ ); 1 sec (except $d, 4 \mathrm{sec}$ ).

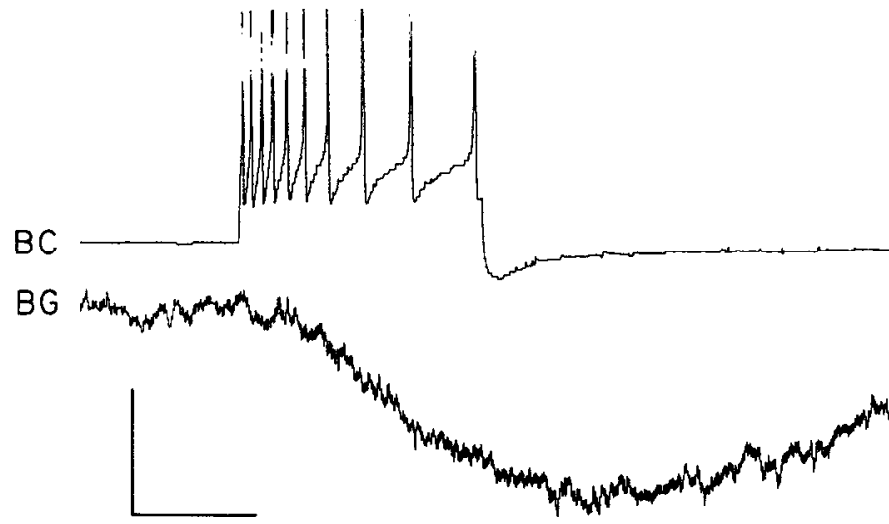

Figure 3. Hyperpolarizing bag cell response evoked by low frequency firing of a buccal neuron. Depolarizing current $(+0.5$ $\mathrm{nA})$ injected into a buccal cell $(B C)$ resulted in low-frequency firing $(6 \mathrm{~Hz}$ during the first second and lower frequency thereafter), which evoked a $3-\mathrm{mV}$ hyperpolarizing response in the bag cell $(B G)$. With the exception of several cell pairs of the 43 functionally connected pairs described in Table I, low-frequency $(<10 \mathrm{~Hz})$ buccal firing was sufficient to evoke a hyperpolarizing bag cell response. Calibration: top trace, $40 \mathrm{mV}$; bottom trace, $2 \mathrm{mV} ; 1.5 \mathrm{sec}$. The buccal cell action potentials were $100 \mathrm{mV}$ in amplitude; their tops are truncated by the chart recorder.

\section{Discussion}

The wide variety of cell types which have been found to exhibit electrotonic coupling (Bennett and Goodenough, 1978; Lowenstein, 1981) has led to the generalization that a communication-competent cell will couple with any other communication-competent cell regardless of its tissue or (within certain limits) its species of origin (Epstein and Gilula, 1977). The situation may, however, be different in the nervous system, the function of which is dependent on a highly specific pattern of intercellular connections. Cultured leech neurons exhibit selectivity in electrotonic synapse formation (Ready and Nicholls, 1979; Fuchs et al., 1981), and neurons in organ-cultured Helisoma ganglia form novel but still selective electrotonic synapses when neurite regeneration is evoked by axotomy (Bulloch and Kater, 1982). The present results support the idea that there is selectivity in the formation of electrotonic connections between nerve cells. In addition they demonstrate at the level of an individual cell that such selectivity is not necessarily due to a lack of communication competence, since a single bag or buccal neuron, which is entirely competent to couple with an adjacent cell of the same type, chooses not to couple with an equally competent neighboring cell of the other type. 

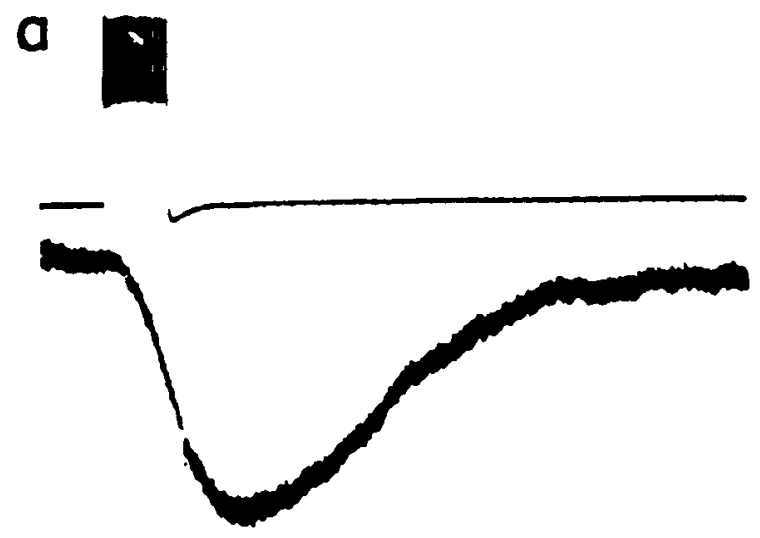

$B C$

BG

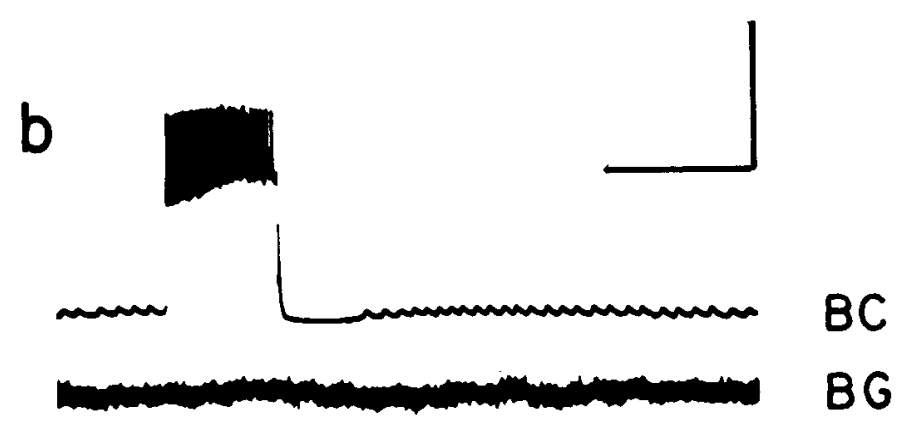

C
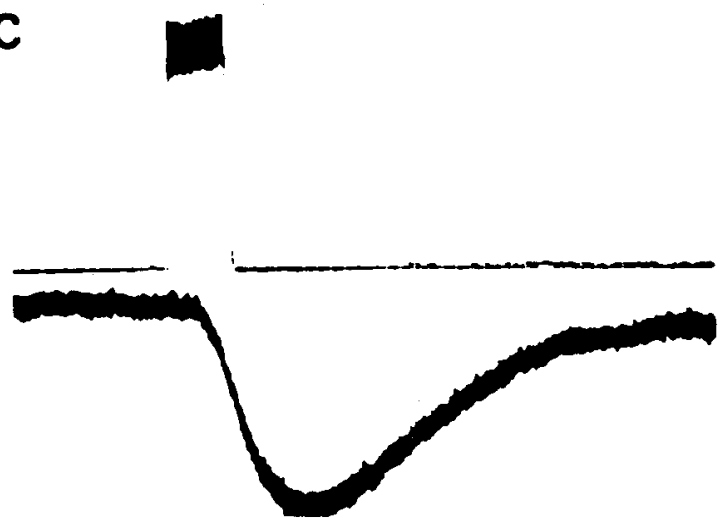

$B C$

BG

Figure 4. Calcium dependence of the buccal-to-bag cell connection. This experiment was done with a pair of cells not connected to any others in the culture dish. a, control. The culture dish was perfused with normal Aplysia saline containing $11 \mathrm{mM} \mathrm{Ca}{ }^{2+}$. Every minute a $2-\mathrm{sec}$ train of approximately 18 action potentials was evoked in the buccal cell (top trace), resulting in a $-17 \pm 1 \mathrm{mV}$ (SD) hyperpolarizing response in the bag cell (bottom trace). $b$ Zero $\mathrm{Ca}^{2+}$. After $12 \mathrm{~min}$ of perfusion with $\mathrm{Ca}^{2+}$-free saline, connectivity is abolished. A 3 sec volley of approximately 28 action potentials in the buccal cell elicits no change in the membrane potential of the bag cell. $c$, recovery. After $6 \mathrm{~min}$ of washing with normal saline, the
TABLE I

Electrotonic and chemical connections in mixed bag-buccal $(B C)$ cell cultures

Data were taken from a large number of experiments similar to that in Figure 2. The number of separate culture dishes used is shown in parentheses. A coupling coefficient ( $\Delta V$ post $/ \Delta V$ pre) $>0.02$ was taken as evidence for an electrotonic synapse. An inhibitory postsynaptic potential (IPSP) $>1 \mathrm{mV}$ was taken as evidence for a chemical interaction. These were the minimum values which we could detect reliably.

\begin{tabular}{cccc}
\hline \multicolumn{3}{c}{$\begin{array}{c}\text { No. of Pairs Coupled/ } \\
\text { Total Pairs Tested }\end{array}$} & $\begin{array}{c}\text { No. of Pairs with IPSP/ } \\
\text { Total Pairs Tested } \\
\text { (BC-bag) }\end{array}$ \\
\cline { 1 - 3 } BC-BC & Bag-bag & Bag-BC & \\
\hline $37 / 41(18)$ & $14 / 15(7)$ & $0 / 79(25)$ & $43 / 71(21)$ \\
\hline
\end{tabular}
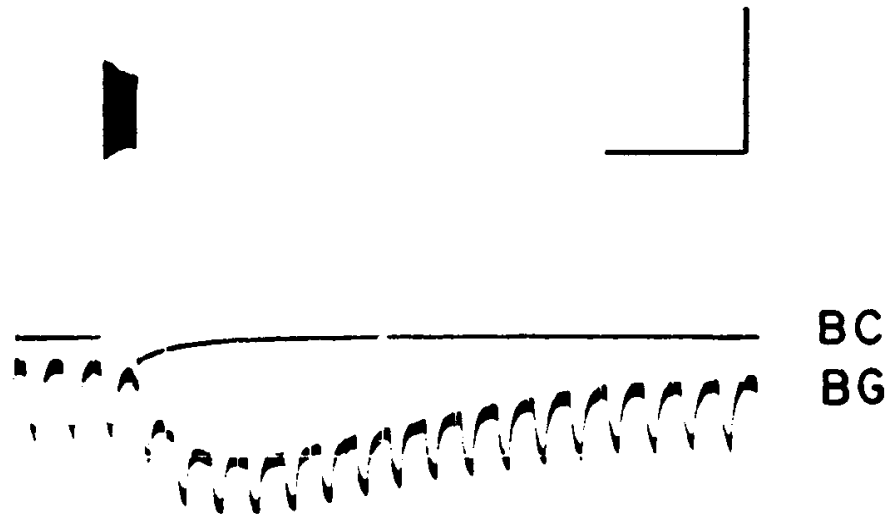

Figure 5. Increase in membrane conductance during the bag cell $(B G)$ response. The bag cell (bottom trace) was injected with hyperpolarizing current pulses $(-0.2 \mathrm{nA}$ for $0.3 \mathrm{sec}$ at 1 $\mathrm{Hz}$ ), which produced voltage deflections of $-10 \mathrm{mV}$. A train of action potentials in the buccal cell $(B C)$ (top trace) elicited a typical hyperpolarizing response in the bag cell $(-13 \mathrm{mV}$ in this example) and caused an approximately 50\% decrease in the amplitude of the voltage deflections, indicative of an approximately 2 -fold increase in the membrane input conductance. Calibration: top trace, $100 \mathrm{mV}$; bottom trace, $20 \mathrm{mV} ; 4 \mathrm{sec}$. This is representative of three separate experiments.

It is important to note that buccal neurons in situ are not a homogeneous population (Gardner, 1971, 1977). However, they do behave homogeneously with respect to electrotonic synaptogenesis in our culture system, in that buccal neurons can form electrotonic synapses with other buccal neurons with high frequency, but none will couple with bag cells. In this respect they resemble the bag cells, which are thought to be homogeneous. Higgins and Burton (1982) have also reported extensive electrotonic coupling among cultured sympathetic neurons grown in a defined medium. We do not understand this phenomenon, although it seems possible that only a selected homogeneous population of buccal neurons will survive under our culture conditions. Alternatively, the neurons

response has returned to near its original amplitude. A volley of 21 action potentials elicits a $-15 \mathrm{mV}$ response. Calibration: top traces, $100 \mathrm{mV}$; bottom traces, $10 \mathrm{mV} ; 4$ sec. This result is representative of four separate experiments. 
may dedifferentiate in culture in such a way that the rules governing the formation of connections between cells are different from those in situ. Such an explanation might account for the extensive electrotonic coupling in pure buccal cultures, since coupling in situ has been reported to be stronger in younger animals (Gardner, 1977). In any event, whatever the explanation is for this homogeneity, its occurrence provides an opportunity to study some aspects of specificity of synapse formation.

This study also raises a number of questions about the formation of chemical connections in these cultures. It is surprising that no buccal-buccal chemical interactions are found, since they do occur in situ (Gardner, 1971, 1977). Again this might be explained by dedifferentiation, or by the selective survival of a non-interacting population of neurons. In addition it is not known whether the buccal-bag connection is indeed a true synapse with morphological specializations. The latency and slow kinetics of the response are also consistent with a neurohormone diffusing across some distance to activate non-synaptic receptors on the target cell (Jan and Jan, 1982). A definitive answer to this question will have to await a detailed ultrastructural characterization of the contacts between bag and buccal neurons.

Finally, in view of the relatively few chemical interactions which we have seen in Aplysia neuronal cultures (in a recent abstract Schacher et al. (1982) describe appropriate chemical connections between cultured abdominal ganglion neurons), the existence of a novel buccal-to-bag cell connection which has not been reported in situ is particularly intriguing. It is important to note that neither the reverse (bag-to-buccal) connection nor bag-bag or buccal-buccal chemical interactions have been found in these cultures. We cannot rule out the possibility that there is some small amplitude and short-lived bag-bag or buccal-buccal chemical interaction which is not detectable because of the high degree of electrotonic coupling, but a long-lasting response similar to the buccal-to-bag interaction would have been readily apparent. One possible explanation for the apparent unidirectionality of this connection is that buccal neurons or other bag cells do not contain receptors to the transmitter(s) released by bag cells, since transmitterreceptor matching is clearly necessary for functional connectivity. Whether such matching is sufficient or whether other factors also contribute to the specificity of connectivity in this system remains to be determined.

\section{References}

Bennett, M. V. L., and D. A. Goodenough (1978) Gap junctions, electrotonic coupling and intercellular communication. Neurosci. Res. Program Bull. 16: 373-486.

Bulloch, A., and S. B. Kater (1982) Neurite outgrowth and selection of new electrical connections by adult Helisoma neurons. J. Neurophysiol. 48: 569-583.

Dagan, D., and I. B. Levitan (1981) Isolated identified Aplysia neurons in cell culture. J. Neurosci. 1: 736-740.

Epstein, M. L., and N. B. Gilula (1977) A study of communication specificity betwen cells in culture. J. Cell Biol. 75: 769-787.

Fischbach, G. D., and P. G. Nelson (1977) Cell culture in neurobiology. In Handbook of Physiology. Section 1: The Nervous System. Vol. 1: Cellular Biology of Neurons, E. R. Kandel, ed., pp. 719-774, Williams \& Wilkins, Baltimore.

Fuchs, P. A., J. G. Nicholls, and D. F. Ready (1981) Membrane properties and selective connexions of identified leech neurons in culture. J. Physiol. (Lond.) 316: 203-223.

Gardner, D. (1971) Bilateral symmetry and interneuronal organization in the buccal ganglia of Aplysia. Science 173: 550 553.

Gardner, D. (1977) Interconnections of identified multiaction interneurons in buccal ganglia of Aplysia. J. Neurophysiol. 40: $349-361$.

Higgins, D., and H. Burton (1982) Electrotonic synapses are formed by fetal rat sympathetic neurons maintained in a chemically defined culture medium. Neuroscience 7: 22412253.

Jan, L., and Y. N. Jan (1982) Peptidergic transmission in sympathetic ganglia of the frog. J. Physiol. (Lond.) 327: 219246.

Kaczmarek, L., M. Finbow, J. P. Revel, and F. Strumwasser (1979) The morphology and coupling of Aplysia bag cells within the abdominal ganglion and in cell culture. J. Neurobiol. 10: 535-550.

Lowenstein, W. (1981) Junctional intercellular communication: The cell-to-cell membrane channel. Physiol. Rev. 61: 829913.

Nelson, P. G. (1975) Nerve and muscle cells in culture. Physiol. Rev. 55: 1-61.

Ready, D., and J. G. Nicholls (1979) Identified neurones isolated from leech CNS make selective connections in culture. Nature 281: 67-69.

Schacher, S., E. Proshansky, and J. S. Camardo (1982) Neurite outgrowth and synapse formation by identified Aplysia neurons in dissociated cell culture. Soc. Neurosci. Abstr. 8: 17.

Wong, R. G., R. D. Hadley, S. B. Kater, and G. C. Hauser (1981) Neuritic outgrowth in molluscan organ and cell cultures: The role of conditioning factors. J. Neurosci. 1: 10081021. 